\section{EPIDEMIOLOGY AND POLICY}

\section{P1-65 ROAD TRAFFIC ACCIDENTS IN ALEXANDRIA, EGYPT: TRENDS OF MORTALITY (2000-2009)}

doi:10.1136/jech.2011.142976c.58
M A Wahab.* High Institute of Public Health, Alexandria, Egypt

Introduction Road traffic accidents (RTA) with their serious social and economic consequences, though preventable, comprise an important cause of death and disability in developing countries, where the problem is increasing rapidly due to rapid motorisation. Nearly three-quarters of road deaths occur in developing countries. It is estimated that RTA will be the second leading cause of disability-adjusted life years in developing countries in the year 2020. This study aims to describe quantitatively the RTAs related mortality in Alexandria, and to identify their trends through 2000-2009.

Methods Data were collected from records of the information and decision support center in Alexandria. Statistical analyses were performed using SPSS 18.0 for windows software. Trends were evaluated using time series seasonal decomposition and ARIMA analyses. Different risks were determined using Poisson regression. Results RTA mortality followed a significant rising trend (cubic model) with the highest incidence rate being in 2008 and 2009. Months from July to October showed the highest seasonal factors. Males were more than three times at risk than females. RTA mortality occurred with a higher incidence for ages above 60 years old and youth (university ages). Also higher rates were calculated for poor and remote districts.

Conclusion Policy makers in Alexandria, Egypt need to recognise Road Traffic Accidents (RTA) as a growing public health crisis, design appropriate policy responses and implement urgent interventions for road safety applicable to the particular mix of Egyptian road use.

\section{P1-66 TRENDS IN NUTRITIONAL INTAKE AND SERUM CHOLESTEROL LEVELS OVER 50 YEARS IN TANUSHIMARU, JAPANESE MEN}

doi:10.1136/jech.2011.142976c.59

${ }^{1} \mathrm{H}$ Adachi, ${ }^{*} \mathrm{Y}$ Hirai, ${ }^{2} \mathrm{M}$ Enomoto, ${ }^{2} \mathrm{~A}$ Fukami, ${ }^{2} \mathrm{M}$ Otsuka, ${ }^{2} \mathrm{~S}$ I Kumagae, ${ }^{2} \mathrm{Y}$ Nanjo, ${ }^{2} \mathrm{E}$ Esaki, ${ }^{2} \mathrm{E}$ Kumagai, ${ }^{2} \mathrm{~K}$ Yoshikawa, ${ }^{2} \mathrm{~K}$ Yokoi, ${ }^{2} \mathrm{~K}$ Ogata, ${ }^{2} \mathrm{E}$ Tsukagawa, ${ }^{2} \mathrm{~A}$ Kasahara, ${ }^{2} \mathrm{~K}$ Murayama, ${ }^{2} \mathrm{~T}$ Imaizumi. ${ }^{1}$ Department of Community Medicine, Kurume University School of Medicine, Kurume, Fukuoka, Japan; ${ }^{2}$ Department of Internal Medicine, Division of Cardio-Vascular Medicine, Kurume University School of Medicine, Kurume, Fukuoka, Japan

Introduction Rapid socioeconomic development in Japan since beginning of the Seven Countries Study in 1958 has brought remarkable changes in lifestyle and dietary patterns. We investigated the relationship between time trends in nutrient intake and serum cholesterol levels in a Japanese cohort of the Seven Countries Study, in Tanushimaru, a typical farming town on Kyushu Island.

Methods Subjects totalled 628 in 1958, 539 in 1977, 602 in 1982, 752 in 1989, 402 in 1999, and 329 in 2009, and all of the subjects were men aged 40-64 years. Eating patterns were evaluated by $24 \mathrm{~h}$ dietary recall from 1958 through 1989, and by a food frequency questionnaire in 1999 and 2009. We also measured serum cholesterol levels in each health examination.

Results The total daily energy intake decreased from $2837 \mathrm{kcal}$ in 1958 to $2289 \mathrm{kcal}$ in 2009 . The carbohydrate intake in percentage of total daily energy intake decreased markedly, from $84 \%$ in 1958 to $58 \%$ in 2009 , in contrast to large increases during this period in protein intake (from $11 \%$ to $16 \%$ ) and fat intake (from $5 \%$ to $22 \%$ ). In proportion to the dramatic change in protein and fat intake, serum cholesterol levels showed large increases (from $152.5 \mathrm{mg} / \mathrm{dl}$ to $207.7 \mathrm{mg} / \mathrm{dl}$ ).

Conclusions In spite of such big dietary changes towards a westernized diet, the incidence of coronary artery disease in a rural Japanese area remains low. However, careful surveillance is needed in the future because of the remarkably increasing intake of fats, especially saturated fatty acids.

\section{P1-67 FACTORS AFFECTING PATIENT'S ADHERENCE TO DIRECTLY OBSERVED TREATMENT (DOT) CARE PRACTICES IN DHAKA CITY}

doi:10.1136/Jech.2011.142976c.60

${ }^{1} \mathrm{M}$ A Hafez, ${ }^{1} \mathrm{M}$ Shahjahan, ${ }^{2} \mathrm{M}$ S Flora, ${ }^{1} \mathrm{~A}$ Afroz, ${ }^{*} \mathrm{~K}$ Kobura, ${ }^{3} \mathrm{~S} \mathrm{M}$ Satter, ${ }^{1} \mathrm{~S} \mathrm{~J}$ Mumu, ${ }^{1} \mathrm{~A}$ Akhter, ${ }^{1} \mathrm{~F}$ Rahman, ${ }^{1} \mathrm{~N}$ Sumi, ${ }^{1} \mathrm{~K}$ Fatema. ${ }^{1}$ Bangladesh Institute of Health Sciences (BIHS), Dhaka, Bangladesh; ${ }^{2}$ National Institute of Preventive and Social Medicine (NIPSOM), Dhaka, Bangladesh; ${ }^{3}$ International Center for Diarrhoeal Disease Research, (ICDDR), Dhaka, Bangladesh

Introduction Directly Observed Treatment Short course (DOTS) was introduced in Bangladesh in 1993. Thereafter case detection and cure rate have increased remarkably. This cross sectional study aimed to estimate proportion of patients adhering to DOT and its influencing factors.

Method A two-stage cluster sampling method was followed. Dhaka city has 90 wards and 159 clinics providing DOT service of which 30 wards (clusters) were selected using systematic sampling technique. A total of 215 Pulmonary TB cases aged ${ }^{3} 15$ years, registered with all the 40 clinics of these 30 clusters were interviewed.

Results Of the respondents $61 \%$ were males. About $65 \%$ were aged between 20 and 39 years, mean age 31 (SD \pm 12.6 ) years, about $50 \%$ had little or no education with average monthly income US\$ 152 $(\mathrm{SD} \pm 110)$ and average family size 5 (range: $1-15)$ living in very poor housing condition. At the time of diagnosis $59 \%$ of the patients were smear +ve. Fifty-two per cent respondents took drug at centre and $48 \%$ at home. Adherence rate at clinic was $100 \%$ and at home $66 \%$-overall $84 \%$ (95\% CI 79.1 to 88.9 ) had adhered to DOT. Association was found between adherence and smear type at start, clinic type (govt or private) and family history of TB $(p<0.05)$. Binary logistic regression suggests type of smear and family history of TB as correlates of adherence.

Conclusion Although respondents belong to low socio-demographic status, adherence rate seems satisfactory. But home level adherence was low. Creation of awareness and appropriate monitoring might improve the situation.

\section{P1-68 EPIDEMIOLOGICAL PATTERN AND BURDEN OF DROWNING IN MAZANDARAN PROVINCE IN IRAN}

doi:10.1136/jech.2011.142976c.61

S Akbarpour, ${ }^{*}$ H Soori, A Khosravi, G khosro, S Azimi. Safety promotion and injury prevention research center, Tehran, Iran

Introduction Drowning is a serious public health problem in the northern provinces of Iran. The aim of this study was to describe the burden of drowning in Mazandaran province, Iran in order to inform public health priority setting and planning.

Methods Data from the Death Registry System, Legal Medicine Organization and the Ministry of Health were used to describe the burden of drowning in Mazandaran province Iran in 2008. The burden of drowning was calculated with using the standard WHO method. 